olemic hemodilution reduce perioperative allogeneic transfusion? A meta-analysis. The International Study of Perioperative Transfusion. Anesth Analg 1998; 86: 9-15.

3 Stover EP, Siegel LC, Parks R, et al. Variability in transfusion practice for coronary artery bypass surgery persists despite national consensus guidelines: a 24-institution study. Institutions of the Multicenter Study of Perioperative Ischemia Research Group. Anesthesiology 1998; 88: 327-33.

\section{In vitro relationship between the blood nafamostat concentration and activat- ed coagulation time}

To the Editor:

The biological half-time of nafamostat (Torii Pharmaceutical, Tokyo, Japan), molecular weight 539.58 , used as an anticoagulant in procedures such as continuous hemodiafiltration (CHDF) is approximately eight minutes. ${ }^{1}$ Anticoagulation in the circuit is maintained adequately, whilst its concentration in the patient's blood decreases rapidly to a level which cannot cause anticoagulation, as measured by the activated coagulation time (ACT). We have routinely calculated the infusion dose of nafamostat using the patient's weight. ${ }^{2}$ If the relationship between the blood nafamostat concentration and ACT is clarified, it may be possible to determine the dose of nafamostat alternatively.

After approval of our Institutional Committee, nafamostat was diluted with $5 \%$ glucose, and six plastic syringes were prepared, containing $0.1 \mathrm{~mL}$ of $5 \%$ glucose, $0.1 \mathrm{~mL}$ of $0.001 \mathrm{mg} \cdot \mathrm{mL}^{-1}$ nafamostat, 0.1 $\mathrm{mL}$ of $0.01 \mathrm{mg} \cdot \mathrm{mL}^{-1}$ nafamostat, $0.1 \mathrm{~mL}$ of 0.05 $\mathrm{mg} \cdot \mathrm{mL}^{-1}$ nafamostat, $0.1 \mathrm{~mL}$ of $0.1 \mathrm{mg} \cdot \mathrm{mL}^{-1}$ nafamostat, and $0.1 \mathrm{~mL}$ of $0.5 \mathrm{mg} \cdot \mathrm{mL}^{-1}$ nafamostat, respectively. $1.9 \mathrm{~mL}$ of blood from ten healthy volunteers was aspirated in turn in the six prepared syringes from an $i v$ catheter followed immediately by measurement of the ACT (ACTester ${ }^{\mathrm{TM}}$, QUEST Medical, Allen, TX, USA). The blood nafamostat concentrations were then $0 \mathrm{~mol} \cdot \mathrm{L}^{-1}$ and approximately $10^{-7}, 10^{-6}, 5 \times 10^{-6}$, $10^{-5}$ and $5 \times 10^{-5} \mathrm{~mol} \cdot \mathrm{L}^{-1}$, respectively.

There was a highly significant relationship between blood nafamostat concentration and ACT. The ACT was prolonged significantly at $5 \times 10^{-6}, 10^{-5}$ and $5 \times$ $10^{-5} \mathrm{~mol} \cdot \mathrm{L}^{-1}$ nafamostat, showing values of $221 \pm 74$, $300 \pm 70$ and $665 \pm 249 \mathrm{sec}$, respectively. (Figure).

During hemofiltration, the ACT should be maintained between 180 and $240 \mathrm{sec}^{3}$ These values correspond to an appropriate nafamostat concentration of

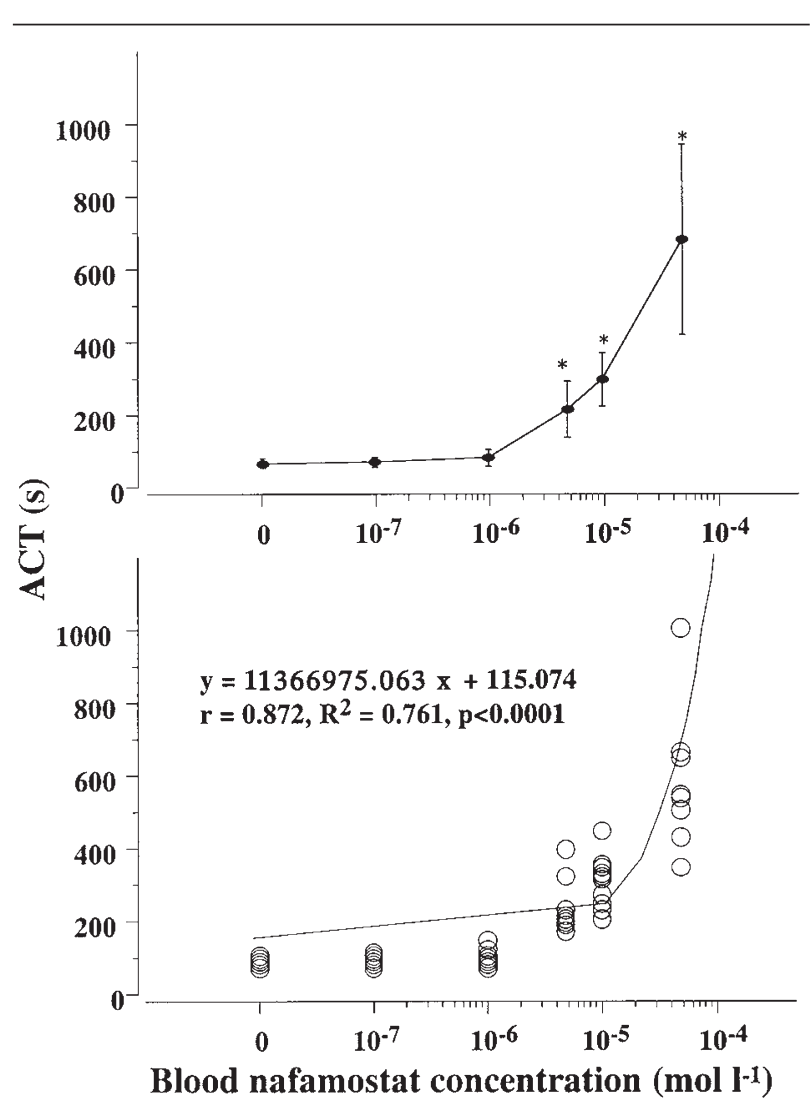

FIGURE The relationship between the blood nafamostat concentration and activated coagulation time (ACT). Upper graph shows values of mean $\pm \mathrm{SD}$ and statistical changes $\left({ }^{*} P<0.05\right.$ vs 0 $\mathrm{mol} \cdot \mathrm{L}^{-1}$ value). Lower graph shows scattergram and regression equation.

0.6 to $1 \times 10^{-5} \mathrm{~mol} \cdot \mathrm{L}^{-1}$, suggesting that $10^{-5} \mathrm{~mol} \cdot \mathrm{L}^{-1}$ is required for blood to pass through the hemofilter safely. In our clinical practice, $0.5 \mathrm{mg} \cdot \mathrm{kg}^{-1} \cdot \mathrm{hr}^{-1}$ nafamostat is usually injected for CHDF. ${ }^{2}$ If the patient weighs 60 $\mathrm{kg}, 0.5 \mathrm{mg} \cdot \mathrm{kg}^{-1} \cdot \mathrm{hr}^{-1}$ nafamostat injected into blood flowing at $100 \mathrm{~mL} \cdot \mathrm{min}^{-1}$ results in a concentration of $10^{-5} \mathrm{~mol} \cdot \mathrm{L}^{-1}$ nafamostat. As an alternative, nafamostat may be injected continuously to result in a circuit blood concentration of $10^{-5} \mathrm{~mol} \cdot \mathrm{L}^{-1}$.

Hiroshi Iwama MD

Kazuhiro Watanabe MD

Shinju Obara MD

Aizuwakamatsu, Japan

\section{References}

1 Aoyama T. Nafamstat mesilate. Drugs of the Future 1984; 9: 747-8. 
2 Hu ZJ, Iwama H, Suzuki R, Kobayashi S, Akutsu I. Time course of activated coagulation time at various sites during continuous haemodiafiltration using nafamostat mesilate. Intensive Care Med 1999; 25: 524-7.

3 Kox WJ, Robr U, Wauer H. Practical aspects of renal replacement therapy. Int J Artif Organs 1996; 19: $100-5$.

\section{Aspiration pneumonia associated with a giant epiglottic cyst after cardiac surgery}

To the Editor:

Epiglottic cysts are found incidentally during induction of general anesthesia and can hamper tracheal intubation. ${ }^{1}$ Several methods have been reported to overcome these situations, however, to our knowledge, there has been no report of postoperative respiratory complications in patients with epiglottic cysts. We describe a patient with a giant asymptomatic epiglottic cyst who developed aspiration pneumonia after cardiac surgery.

A 7l-yr-old man (height $154 \mathrm{~cm}$, weight $42 \mathrm{~kg}$ ) was scheduled to undergo coronary artery bypass grafting. During induction of general anesthesia, a giant epiglottic cyst was found (Figure). Though manual ventilation was easy, the cyst had almost obstruct-

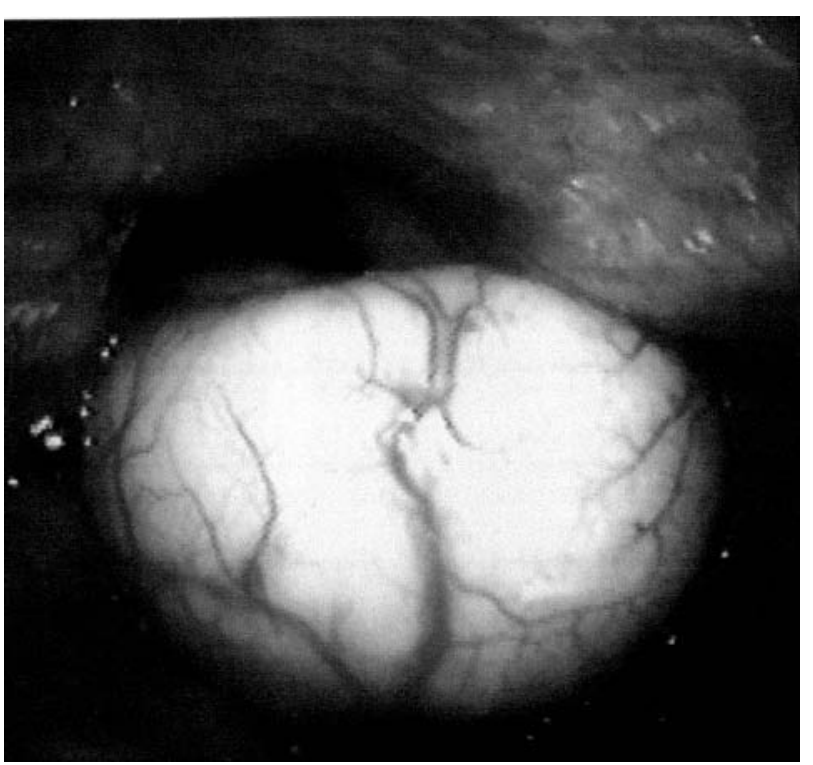

FIGURE A giant epiglottic cyst was found incidentally at laryngoscopy. The larynx was almost obstructed by the cyst. ed the larynx and tracheal intubation was difficult. The surgery was carried out uneventfully and he was admitted to the intensive care unit for postoperative management. On postoperative day one (PODl), he was extubated and his respiratory state was stable. On POD2, he was able to drink water and the cough reflex was present. Immediately following the reintroduction of solid food, he developed aspiration pneumonia of the right lower lobe. Mechanical ventilation and administration of antibiotics proved effective and the cyst was removed surgically on POD5 under general anesthesia. The postoperative course after cystectomy was uneventful and oral intake was normal.

There are several factors that increase the risk for aspiration pneumonia after surgery; namely, loss of protective airway reflexes, vomiting, pregnancy, obesity, diminished level of consciousness, anatomic distortion of the airway and a history of cerebrovascular disease. ${ }^{2,3}$ Especially after cardiac surgery, age and duration of intubation are independent predictors of swallowing dysfunction. ${ }^{4}$ In our patient, age, the residual effects of anesthetics, the use of transesophageal echocardiography, duration of intubation and anatomic distortion due to the giant epiglottic cyst are all possible factors explaining aspiration. We cannot tell which factor was predominant. However, the presence of this large epiglottic cyst may have resulted in postoperative epiglottic dysfunction and aspiration of solid food.

\section{MinHye So MD \\ Kazuya Sobue MD PhD \\ Hajime Arima MD \\ Tetsuro Morishima MD \\ Masatoshi Fukumoto MD \\ Sayuki Tanaka MD \\ Hiroshi Ando MD PhD \\ Obazaki, Japan \\ Hirotada Katsuya MD PhD \\ Nagoya, Japan}

\section{References}

1 Dada MA. Laryngeal cyst and sudden death. Med Sci Law 1995; 35: 72-4.

2 Mecca RS. Pulmonary aspiration syndrome. In: Kirby RR, Gravenstein N, Lobato EB, Gravenstein JS (Eds.). Clinical Anesthesia Practice, 2nd ed. Philadelphia: W.B. Saunders Company; 2002: 101-3.

3 Harrington $O B$, Duckworth JK, Starnes CL, et al. Silent aspiration after coronary artery bypass grafting. Ann Thorac Surg 1998; 65: 1599-603.

4 Hogue CW Jr, Lappas GD, Creswell LL, et al. Swallowing dysfunction after cardiac operations. 